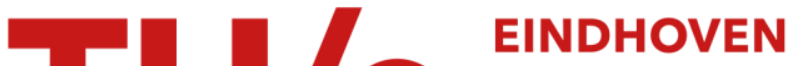 UNIVERSITY OF TECHNOLOGY
}

\section{Contact mechanics of high-density polyethylene: Effect of pre- stretch on the frictional response and the onset of wear}

\section{Citation for published version (APA):}

Looijmans, S. F. S. P., Anderson, P. D., \& van Breemen, L. C. A. (2018). Contact mechanics of high-density polyethylene: Effect of pre-stretch on the frictional response and the onset of wear. Wear, 410-411, 142-148. https://doi.org/10.1016/j.wear.2018.06.009

DOI:

10.1016/j.wear.2018.06.009

Document status and date:

Published: 15/09/2018

\section{Document Version:}

Accepted manuscript including changes made at the peer-review stage

\section{Please check the document version of this publication:}

- A submitted manuscript is the version of the article upon submission and before peer-review. There can be important differences between the submitted version and the official published version of record. People interested in the research are advised to contact the author for the final version of the publication, or visit the $\mathrm{DOI}$ to the publisher's website.

- The final author version and the galley proof are versions of the publication after peer review.

- The final published version features the final layout of the paper including the volume, issue and page numbers.

Link to publication

\section{General rights}

Copyright and moral rights for the publications made accessible in the public portal are retained by the authors and/or other copyright owners and it is a condition of accessing publications that users recognise and abide by the legal requirements associated with these rights.

- Users may download and print one copy of any publication from the public portal for the purpose of private study or research.

- You may not further distribute the material or use it for any profit-making activity or commercial gain

- You may freely distribute the URL identifying the publication in the public portal.

If the publication is distributed under the terms of Article 25fa of the Dutch Copyright Act, indicated by the "Taverne" license above, please follow below link for the End User Agreement:

www.tue.nl/taverne

Take down policy

If you believe that this document breaches copyright please contact us at:

openaccess@tue.nl

providing details and we will investigate your claim. 


\title{
Contact mechanics of high-density polyethylene: Effect of pre-stretch on the frictional response and the onset of wear
}

\author{
Stan F.S.P. Looijmans, Patrick D. Anderson, Lambèrt C.A. van Breemen* \\ Polymer Technology, Department of Mechanical Engineering, Eindhoven University of Technology, P.O. Box 513, 5600 MB Eindhoven, \\ The Netherlands
}

\begin{abstract}
Nowadays, in many applications metal parts are replaced by light-weight polymer products. As a result of the processing history, these polymer fabricates are, more often than not, anisotropic, leading to a direction dependent mechanical performance. Recently we showed the frictional response of isotactic polypropylene is improved by pre-stretching the crystalline network. In the present work, the scratch response of isotropic high-density polyethylene (HDPE) is compared with that of several pre-stretched samples of the same material, subjected to a single-asperity contact with a rigid diamond indenter. The surface penetration and lateral force are measured in-situ for a range of applied loads and sliding velocities. In the direction perpendicular to the orientation, the observed response is comparable to that of isotactic polypropylene (iPP). Contrary, in the direction parallel to the oriented crystals abrasive wear is observed in HDPE already for relatively low applied loads. As the amount of anisotropy increases, the wear-rate also increases, leading to a decrease in global scratch resistance of these materials. The discrepancies between iPP and HDPE are explained by the intrinsic material behaviour; the lack of strain softening in HDPE prevents strain localization, hence the ever increasing local stress reaches its maximum value and brittle machining is observed.
\end{abstract}

Keywords: Contact mechanics, Scratch testing, Polymers, Sliding friction, Sliding wear, Micro-scale abrasion

\section{Introduction}

Over the last decades, polymers are increasingly used in many types of applications due to their wide variety of physical properties combined with a low density. Numer-

5 ous studies on the mechanical performance of these materials have lead to the application of polymers for demanding purposes, e.g. medical implants [1,6]. A challenging subject in dynamic loading where two or more relative moving parts are in contact, is the understanding 10 of friction and wear between these parts, in a controlled manner [7-10]. The dissipation of energy due to friction facilitates brittle machining, therewith reducing the lifetime of a product. To circumvent the problem of having a complex loading condition or contact geometry, a so-called

15 single-asperity sliding friction experiment or "scratch test" is considered [11, 12].

Even though this test method is well-defined in terms of geometry, applied load and sliding velocity, the contact area between indenter and test specimen is often poorly 20 determined; conventionally it is modelled as ideally elastic, ideally plastic or a combination of both [7, 12 14. However, for viscoelastic materials, this approximation is not valid, resulting in lifetime predictions that are often

\footnotetext{
*Corresponding author

Email address: L.C.A.v.Breemen@tue.nl (Lambèrt C.A. van Breemen)
}

wrong. Therefore, in the recent past, dedicated experimen25 methods have been employed to study local contact phenomena qualitatively $[15+22$, and quantitatively 23,25$]$. Because of their transparency [26, 27] and well-determined deformation kinetics [28 32, often an isotropic, glassy material is used.

In practice however, from a processing perspective the use of semi-crystalline polymers is desired. Upon cooling from the melt, these materials partially crystallize, and their final mechanical performance is determined by the pressure, cooling-rate and flow-rate 33 35. As a result, the polymer product is, more often than not, anisotropic, i.e. its microstructure is spatially dependent. In our previous work 25] we demonstrated the improved scratch resistance of isotactic polypropylene (iPP) by pre-stretching the crystalline network. The oriented crystals reduce the surface penetration by increasing the lateral stiffness, while the friction force is reduced by a factor of two when sliding in orientation direction.

In this work we extend the study of anisotropy to another widely used polyolefin: high-density polyethylene (HDPE). Following the same rationale as for iPP, an improved scratch resistance by pre-stretching HDPE is expected. Remarkably, the lack of strain softening in HDPE leads to the opposite effect; when sliding in orientation direction, strains are not able to localize, hence the accumulation of stress in the bow wave leads to local fracture 
and eventually in abrasive wear.

\section{Materials and methods}

Materials and sample preparation

110

A high-density polyethylene blow-moulding grade, B6246LS

with melt flow index $0.7\left(190{ }^{\circ} \mathrm{C} / 2.16 \mathrm{~kg}\right)$, kindly provided by SABIC, is used for the isotropic and oriented polyethylene samples. To prepare isotropic samples, pellets are molten on a hot-stage at $200{ }^{\circ} \mathrm{C}$ for 10 minutes 115 and manually compressed between two microscope glass

60 plates of $1 \mathrm{~mm}$ thickness. The thermo-mechanical history is erased by persevering the temperature of $200{ }^{\circ} \mathrm{C}$ for another 5 minutes, whereafter the samples are cooled between aluminum blocks, mimicking the cooling rates 120 present in the cold press that is used producing the basic

65 material for the oriented HDPE samples. For these samples, pellets are heated for 30 minutes to $200{ }^{\circ} \mathrm{C}$ in a steel mould ( $\left.200 \times 200 \times 12 \mathrm{~mm}^{3}\right)$, sandwiched between a stack of steel plates $(1 \mathrm{~mm})$ and aluminum sheets $(0.1 \mathrm{~mm}) .125$ Stepwise load is applied to a final value of $200 \mathrm{kN}$. This

70 pressure is maintained for 5 minutes, and subsequently the stack is manually placed in a water-cooled press and quenched to $15{ }^{\circ} \mathrm{C}$. The crystallinity of these samples is checked using wide-angle X-ray diffraction and is found to be $72 \%$.

75 Solid-state orientation of the compression moulded plates is done by DSM (Geleen, The Netherlands) by means of stepwise calendering the samples at a temperature of $120^{\circ} \mathrm{C}$ to a final draw ratio (DR) of 4,6 and 8 , in the following addressed as DR-4, DR-6 and DR- 8 respectively.

Besides isotropic and oriented HDPE samples, oriented ${ }_{135}$ iPP tapes of DR-1.1, DR-2 and DR-5 are used for comparison with HDPE. A continuous film of highly stereo-regular homopolymer, kindly provided by Borealis, with weightaverge molecular weight $\mathrm{M}_{\mathrm{w}}=365 \mathrm{~kg} / \mathrm{mol}$ and polydispersity index of 5.4 is extruded using a single-screw extruder ${ }_{140}$ (Davis-Standard Limited). Subsequently the extrudate is quenched to $15^{\circ} \mathrm{C}$ and collected on a spool. The relevant properties and detailed processing history of the isotactic polypropylene are given in our previous work [25].

\section{Mechanical testing}

Dogbone shaped samples with a parallel section with dimensions of $12 \mathrm{~mm}$ x $5 \mathrm{~mm}$ are cut from the calendered sheets in the two principal directions; parallel and perpendicular to the oriented crystals, in the remainder of this 150 work denoted by machine direction (MD) and transverse direction (TD), respectively. Uniaxial tensile experiments at an engineering strain-rate of $\dot{\epsilon}_{e}=10^{-3} \mathrm{~s}^{-1}$ are performed on a Zwick Z5.0 universal tensile tester, equipped of $0.1 \mathrm{MPa}$ is applied at the beginning of each experiment to ensure a positive tensile stress. Tests are performed in duplicate, to ensure reproducibility.

Single-asperity sliding friction experiments are performed load and sliding velocity are applied to the sample and the surface penetration and lateral force are measured. A conical, diamond indenter tip geometry, with a cone angle of $90^{\circ}$ and a top radius of $50 \mu \mathrm{m}$ is used to apply normal loads ranging from 100 to $500 \mathrm{mN}$. Two rotational motors control the linear, in-plane motion and are able to apply sliding velocities over three decades of magnitude. Scratch tests with a length of $1 \mathrm{~mm}$ and $10 \mathrm{~mm}$ are performed at scratch velocities 1,10 and $100 \mu \mathrm{m} / \mathrm{s}$, all at room temperature. Each combination of sliding velocity and normal force is applied at least three times to check reproducibility of the steady-state penetration depth and friction force.

The residual scratch profile, i.e. the topography after complete relaxation is examined using an optical profilometer. A Sensofar Pl $\mu$ 2300, equipped with a Nikon Plan Fluor 50x/0.80 EPI lens, is moved along the vertical axis, collecting three-dimensional profiles at a resolution of $0.2 \mu \mathrm{m}$. The surface roughness of all samples is checked and found to be well below $1 \%$ of the penetration depth.

\section{Results and discussion}

The contact mechanics of isotropic and oriented HDPE samples are studied by means of scratch tests. A normal load varying between $100 \mathrm{mN}$ and $500 \mathrm{mN}$ is applied via a rigid, diamond indenter tip of given dimensions to the polymer substrate. After load application, the sample is subjected to a sliding velocity ranging from 1 to $100 \mu \mathrm{m} / \mathrm{s}$. A complex stress field arises in the sample; the material below, and in front of the indenter tip is compressed and pushed forward, leading to a tensile stress behind the tip. In the transition zone between tensile and compressive stresses, i.e. the zone near the indenter tip, contact friction induces large shear stresses. The viscoelastic nature of the polymer substrate causes the indenter tip to be lifted as a bow wave develops in front of it, stabilizing the area of contact. In-situ the momentary surface penetration is measured via the tip displacement, as well as the lateral friction force via leaf springs in the sample support table.

Each combination of normal load and sliding velocity is applied at least three times, to check reproducibility. Average values of the steady-state in-situ penetration depth and lateral force measured on isotropic HDPE (ISO) are shown in Figure 1a and Figure 1b, respectively. Each data point represents the steady-state value measured between $400 \mu \mathrm{m}$ and $900 \mu \mathrm{m}$ along the scratch, averaged over three scratches. Upon increasing normal load, local stresses and local strains increase, and as a result thereof the steadystate surface penetration increases. The rate dependency of the penetration depth increases with increasing load, because a larger fraction of the deformation becomes viscoplastic in nature. The lateral force, determined by the shape and size of the bow wave, increases with increasing surface penetration. More material is displaced when the tip penetrates the surface deeper, increasing the area of 

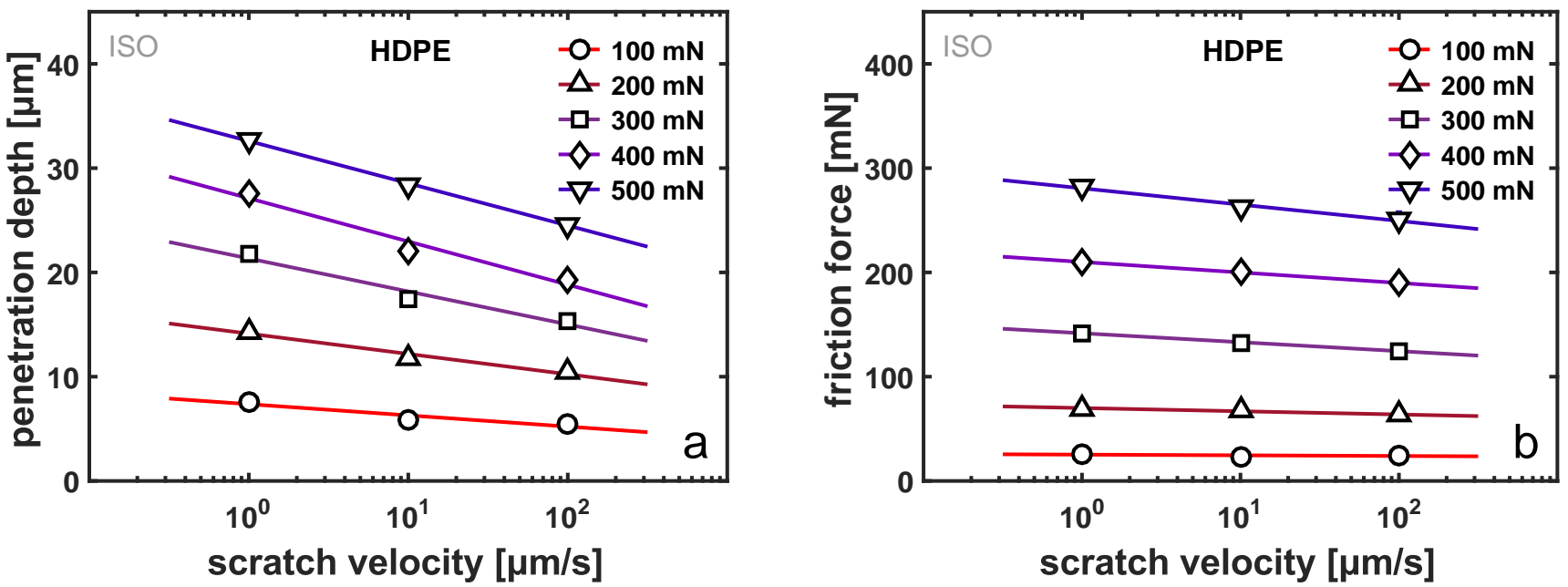

Figure 1: a) Average steady-state penetration depth of isotropic HDPE for various combinations of sliding velocity and applied normal load. b) Corresponding lateral force measurements. Errorbars indicate the standard deviation of the steady-state regime of three scratches, but are smaller than the marker size. An example of the remarkable repeatability can be seen in Figure 3

contact, local stresses and local strains. This combined ${ }_{195}$ effect results in a higher lateral force, while it does not influence the velocity dependency. From the intrinsic behaviour measured by Kanters et al. 36] it is deduced that the large-strain deformation behaviour is hardly affected by the applied strain-rate.

Comparing the obtained results on isotropic HDPE with the previously reported results on isotropic iPP [25], the different material response is clearly seen. HDPE has a yield stress of $30 \mathrm{MPa}$, which is substantially lower than that of iPP (43 MPa) measured under the same conditions, 205 hence in the case of HDPE the indenter penetrates significantly deeper into the surface. The difference in post-yield behaviour between these two materials, can be seen from the lateral force measurements; even though HDPE has a considerably deeper penetration depth, the lateral force 210 is lower compared to iPP. This can be explained by the lack of strain softening in HDPE. Strain softening, i.e. the decrease in true stress after the yield point, leads to strain localization. This local accumulation of plastic strains exceeds the maximum strain in the case of iPP, and hence 215 local brittle failure leads to crack initiation in the center of the scratch. In the case of HDPE, no intrinsic strain softening is present, and the maximum strain is never reached. It is important to note that even though HDPE is lacking intrinsic softening, geometrical effects may lead to strain 220 localization in the material. In a scratch test setup geometrical localization in the center of the scratch is prevented by symmetry of the scratch, while in the bow wave this phenomenon may occur. However, dedicated numerical simulations of the scratch response are indispensable to225 quantify the amount of strain localization and its position in the material upon scratching.

To characterize the anisotropy in HDPE, dog-bone shaped test specimens are machined from the calendered sheets and used for uniaxial tensile testing. The tensile stress as function of engineering strain is measured and shown in Figure $2 \mathrm{a}$ for an engineering strain-rate of $\dot{\epsilon}_{e}=$ $10^{-3} \mathrm{~s}^{-1}$. By orienting the crystal network, the tensile response becomes highly anisotropic; in orientation direction (MD) the maximum stress increases with increasing draw ratio, while the strain-at-break is decreased. In the direction perpendicular to the crystal orientation (TD) the maximum stress is independent of the amount of orientation. The strain-at-break decreases in this direction because of the orientation of the entangled amorphous network. The stress-strain curves measured in TD on the samples DR-6 and DR-8 break before the yield point.

Although the increase in maximum stress in MD as a result of pre-stretching HDPE is considerable, it is less pronounced as for iPP, see Figure 2b. For an oriented iPP sample with DR-2, the maximum stress is already increased by a factor of three, while for the same effect in HDPE a draw ratio of at least four is required. This implies that for a certain increase in maximum stress a lower draw ratio is sufficient, which preserves ductility in iPP as compared to HDPE, where higher draw ratios are enforced.

Sliding friction experiments are performed on the pre-stretched HPDE samples in machine and transverse direction. By solid-state orientation of the samples a pretensioned crystalline network is formed in the (in-plane) machine direction. Along with that, the lateral stiffness, i.e. the stiffness in the normal direction (ND) is increased. The surface penetration, dominated by the transverse viscoelasticity, therefore reduces with increasing amount of orientation. An example of the in-situ response during a scratch test, Figure 3 shows for isotropic HDPE and a 

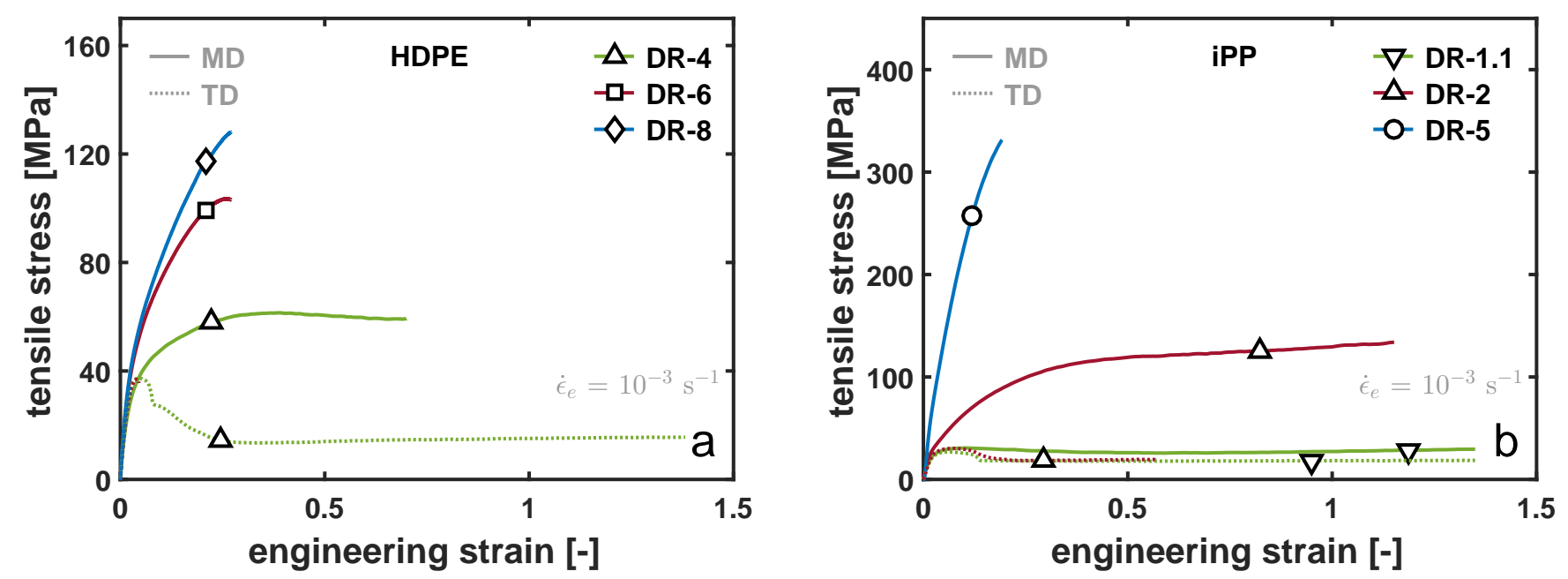

Figure 2: Tensile response of pre-stretched a) HDPE films and b) iPP films (data adopted from our previous work 25]), subjected to uniaxial elongation at an engineering strain-rate of $\dot{\epsilon}_{e}=10^{-3} \mathrm{~s}^{-1}$. Draw ratio and orientation direction are indicated in the plots. The effect of orientation is more pronounced for iPP; note the different scale on the y-axis.

sample with DR-4 in TD the surface penetration and cor-

It should be noted that for both samples three curves are presented, indicating the remarkable reproducibility of the results. The initial instability of the forming bow wave 245 is less pronounced in the oriented samples than in the opic sample, which indicates that with pre-stretching the oriented network becomes more elastic, and viscosity effects are suppressed. Due to the decreasing surface penetration, the friction force is decreased, and therewith the 250 energy dissipation.

The steady-state surface penetration and friction force for various combinations of applied load and sliding velocity, measured in the transverse direction of the oriented HDPE samples, are summarized in Figure 4. With increasing normal load the penetration depth, and as a result thereof the friction force, is increased. The absolute value of this depth is independent of the draw ratio, which is in good agreement with the obtained tensile response in the transverse direction, as shown in Figure 2a. Similarly to iPP [25], the surface penetration is mainly governed by the small strain material response. The velocity dependency of the penetration depth, however, is decreased by increasing the amount of pre-stretch. As discussed be-
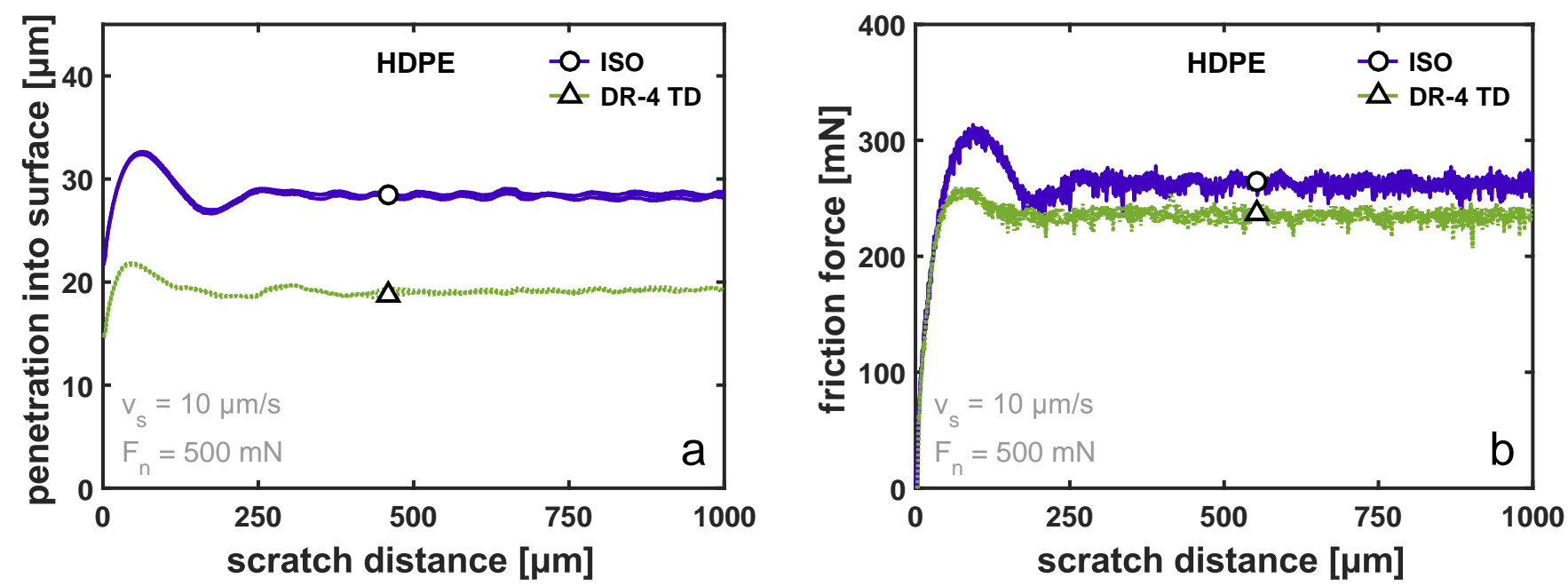

Figure 3: a) In-situ surface penetration for isotropic and pre-stretched HDPE in transverse direction. After the initial indentation a steadystate develops. b) Corresponding in-situ frictional force measurement. For both the surface penetration and lateral force three scratches are shown, indicating the reproducibility. 

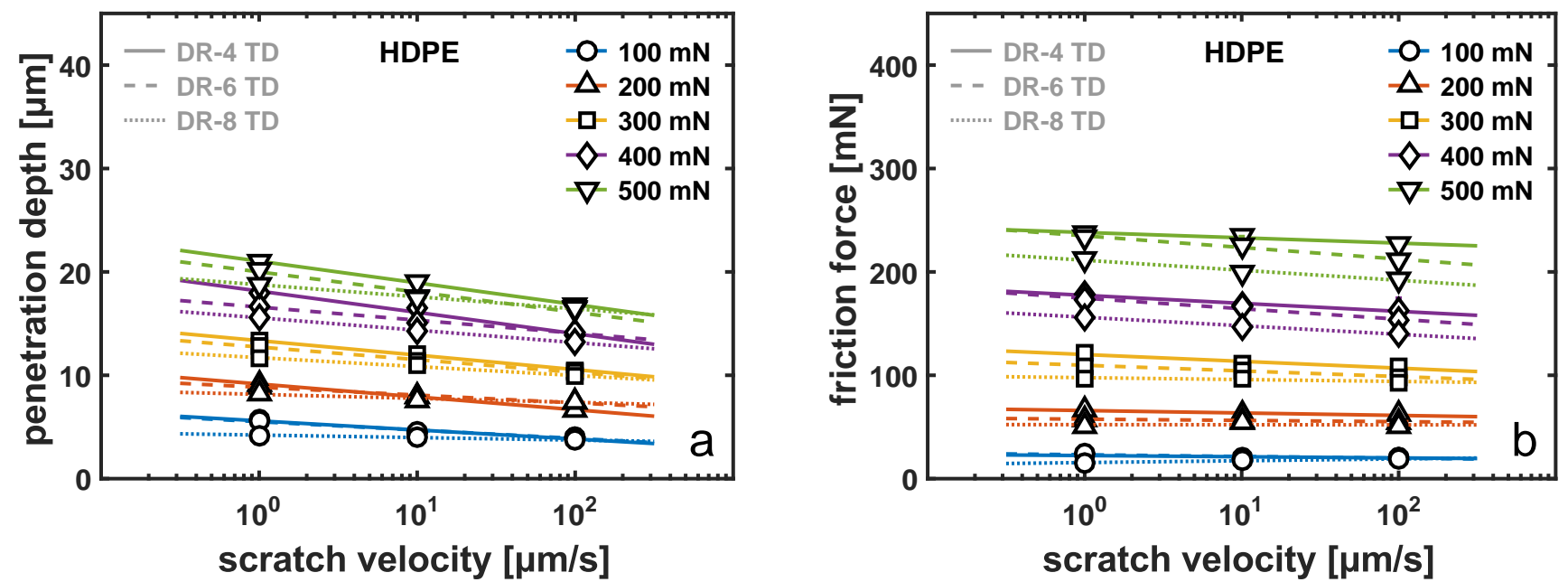

Figure 4: Combined results of a) steady-state penetration depth and b) steady-state friction force for various draw ratios in transverse direction. Each data point represents the average steady-state value of three scratch tests, errorbars are smaller than the marker size. Despite a slight decrease in the velocity dependency, the scratch response in transverse direction is independent of the amount of pre-stretch.

fore, the increase in lateral stiffness enforced by solid-state drawing increases the elasticity in the material, reducing the rate dependency of the scratch response.

When the in-situ scratch response of oriented $\mathrm{HDPE}_{290}$ in TD (Figure 4) is compared with the isotropic response (Figure 1), an improvement by orienting the crystal network is observed; for the same loading condition, i.e. applied load and sliding velocity, the penetration depth is significantly reduced and along with that the frictional ${ }_{295}$ resistance. This conclusion however, is only valid in a load controlled application. Considering a fixed penetration depth, e.g. $22 \mu \mathrm{m}$, Figure $1 \mathrm{a}$ shows that isotropic HDPE is able to withstand $300 \mathrm{mN}$ of applied load, resulting in a lateral force of $150 \mathrm{mN}$, while in the case of oriented HDPE (TD) the friction force is $230 \mathrm{mN}$ under an applied load of $500 \mathrm{mN}$. This implies a very different stress field around the indenter tip. Therefore, dedicated development and propagation of the bow wave, and the underlying stress distribution.

After each scratch experiment, the material is given one week for complete relaxation, and subsequently three(topographical patterns are acquired using the Sensofar Pl $\mu 2300$ optical profilometer. From these patterns, the average residual scratch depth is calculated in the region where in-situ a steady-state was observed. The percentage of elastic recovery of the ISO, DR-4, DR- 6 and -8 samples is shown in Figure 5 , where the errorbars indicate the range of percentages for various sliding velocities. Increasing the normal load increases the fraction of plastic deformation in the sample, hence for isotropic and moderately oriented samples the recovery decreases with applied load. With increasing draw ratio, the recovery strongly increases, to a remarkable value of $95 \%$ for DR-8, where it is independent of the applied load.

Analogous to the previously discussed scratch tests in transverse direction, sliding friction experiments are performed in the machine direction of the three pre-stretched HDPE samples, for all test conditions previously used to characterize the isotropic samples and the transverse direction of the oriented samples. A typical scratch response is shown in Figure 6 a for a scratch distance of $1 \mathrm{~mm}$. At the onset of sliding, the viscoelasticity causes a bow wave to develop, comparable to other materials. However, when sliding beyond a scratch distance of $250 \mu \mathrm{m}$, the penetra-

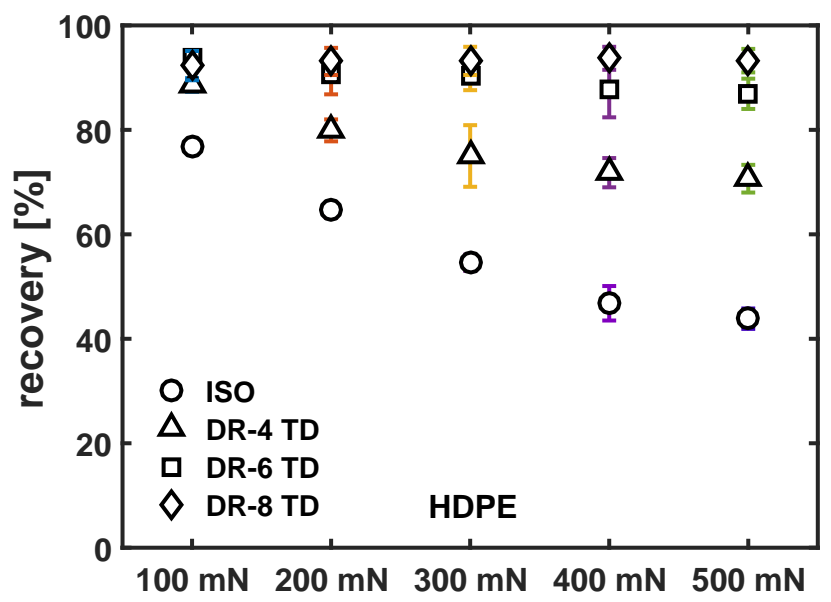

Figure 5: Elastic recovery percentages for various applied normal loads on isotropic HDPE and oriented HDPE samples tested in the direction perpendicular to the crystal orientation. Error bars indicate the range of recovery percentages for different sliding velocities. Upon increasing amount of pre-stretch, the recovery increases to over $95 \%$, even after application of high normal loads. 

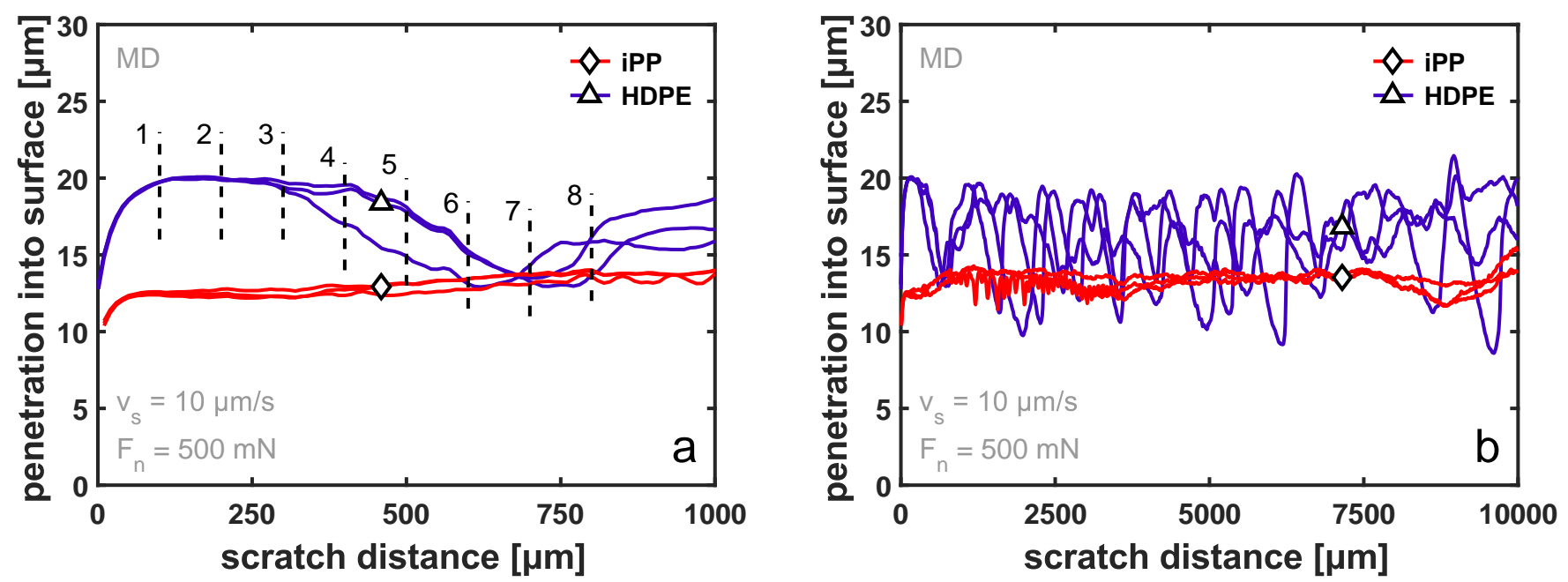

Figure 6: Pentration into the surface as function of scratch distance for scratch tests at highly oriented HDPE (DR-8) and iPP (DR-5) in machine direction. The applied normal load is $500 \mathrm{mN}$ and the sliding velocity $10 \mu \mathrm{m} / \mathrm{s}$, as indicated. a) Total scratch length of $1 \mathrm{~mm}$, b) total scratch length of $10 \mathrm{~mm}$. iPP displays a steady-state regime while HDPE has an oscillating surface penetration with an amplitude in the order of $50 \%$ of the total surface penetration.

tion depth suddenly decreases, implying that the indenter tip is being lifted from the material. Upon further sliding, the penetration depth increases again. To further investigate this unexpected phenomenon, the scratch length is 335 increase to $10 \mathrm{~mm}$, see Figure 6b. A dynamic instability is found, being fairly periodic, with an amplitude up to $50 \%$ of the maximum surface penetration. Intuitively, lateral orce measurements (not shown) display a comparable signal, inversely proportional to the surface penetration, yet 340 with the same frequency. As a result, no steady-state penetration depth and friction force can be reported. Similar experiments are performed on the iPP DR-5 sample that dynamic phenomenon is found.

Since the onset and the period of the phenomenon are reproducible, the "time evolution" thereof is studied by stepwise varying the scratch length from $100 \mu \mathrm{m}$ up to $1000 \mu \mathrm{m}$, at an applied load of $500 \mathrm{mN}$ and sliding velocity of $10 \mu \mathrm{m} / \mathrm{s}$ of the DR-8 HDPE sample. The optical micrograph presented in Figure 7 demonstrates this evolution. The number of each scratch corresponds with the respective length as indicated in Figure 6a. From the top view the structure evolution of the bow wave is clearly demonstrated; the scratches indicated with the numbers 1, 2 and 3 develop a bow wave, which is quasi steady in scratch 4. Upon further sliding, scratch 5, 6 and 7, the pile-up on the sides of scratch behind the indenter tip, steepens, indicating a large local stress field even after the passing of the tip. This particular stress field leads to large tensile stresses in the bow wave and causes the entire bow wave to harden, lifting the tip from the sample. Finally, the tensile stress locally reaches its maximum value, recall Figure 2a, local fracture and abrasive wear is observed, as is demonstrated by scratches numbered 9 and 10 . Thereafter, the indenter tip is pushed over the residual bow wave and the process starts again, leading to the oscillating surface penetration and lateral force.

Depending on the draw ratio and the applied test parameters, the frequency of the tip slipping over the bow wave varies. For the lower normal loads $(100 \mathrm{mN}$ and $200 \mathrm{mN}$ ) the amplitude of oscillation is negligible. For a relatively low draw ratio, e.g. DR-4, the maximum stress the material can withstand (Figure 2a is also relatively

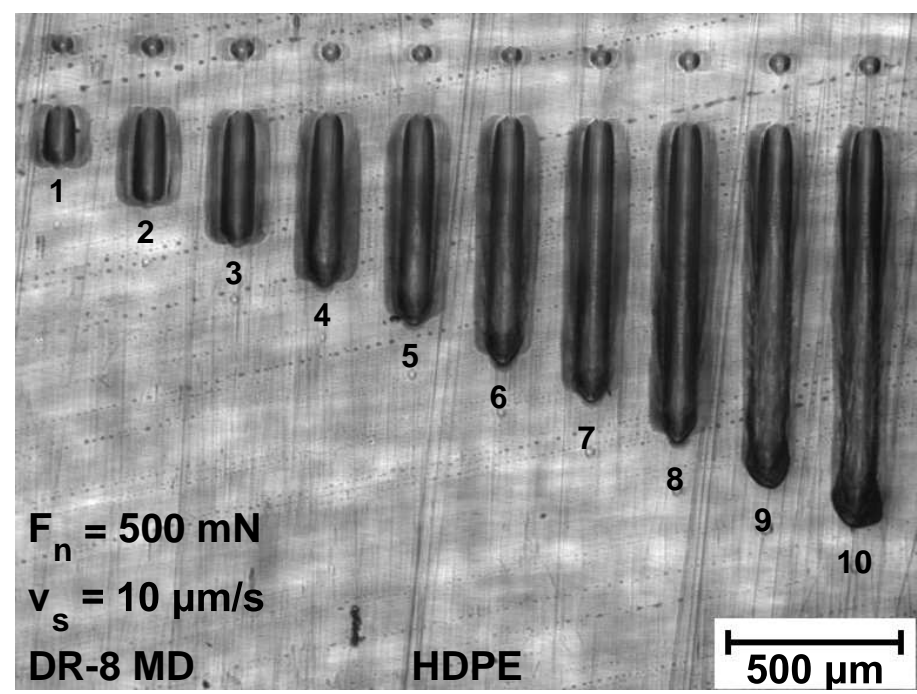

Figure 7: Scratch tests of various lengths performed on highly oriented (DR-8) HDPE in machine direction. The numbers correspond to those in Figure 6a The sliding direction is from top to bottom. Upon increasing scratch length, local strains in the bow wave increase, leading to a large circumferential tension around the indenter tip. Once the local stresses exceed the maximum tensile stress, abrasive wear is observed, see scratch 9 and 10 . 

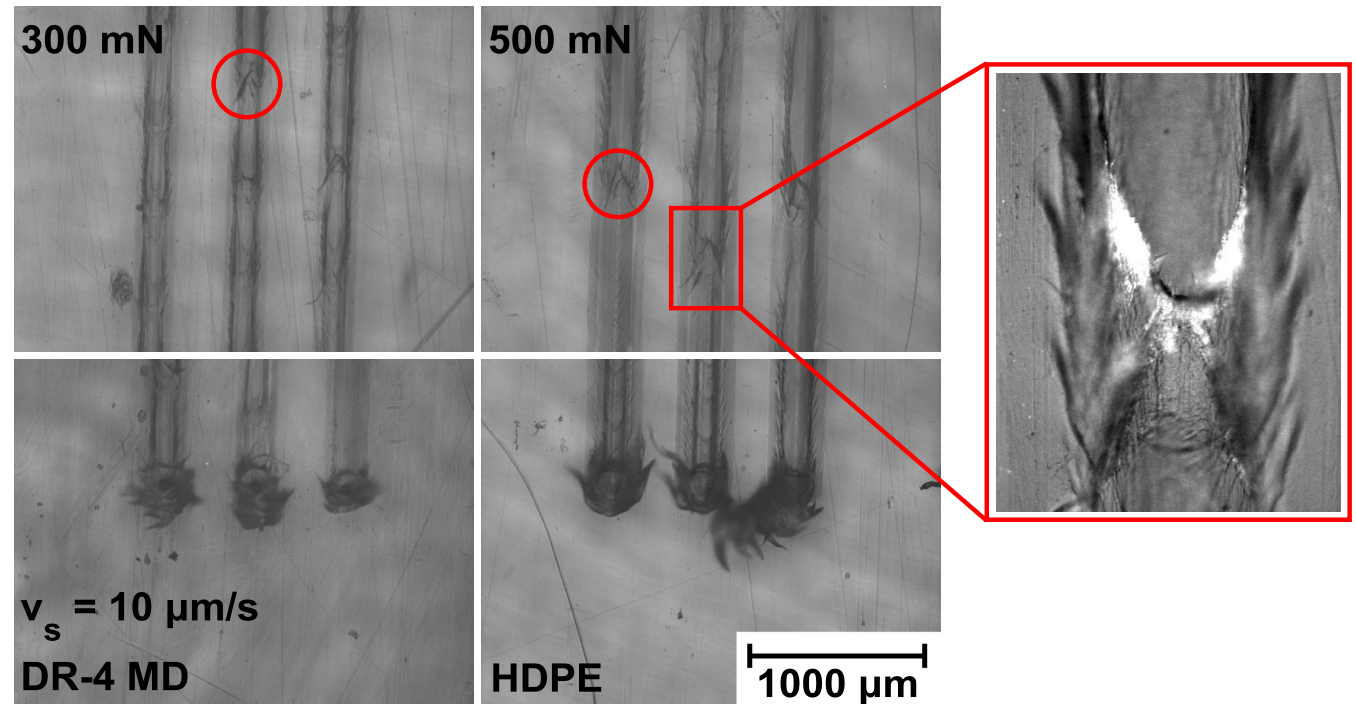

Figure 8: Periodic fracture of the bow wave on the surface of the mid-part of the scratch (top micrographs, encircled and zoom) for an applied load of $300 \mathrm{mN}$ and $500 \mathrm{mN}$. Bottom micrographs show the accumulation of material in front of the tip, i.e. local abbrasive wear, at the end of the scratch.

low, hence the frequency of the phenomenon is highest. On the other hand, with increasing normal load the frequency decreases, because in this case lifting the tip is more difficult when the applied load is higher. The amount of wear however, drastically increases with applied load, as360 is shown in Figure 8 For a normal load of $300 \mathrm{mN}$ (left) and $500 \mathrm{mN}$ (right) a section of the mid-part of the scratch (top) is shown, as well as the end of the scratches (bottom). The micrographs of the mid sections demonstrate scratch ends demonstrate the increased amount of wear with application of a higher load. Following the same rationale, for a higher draw ratio the frequency is lower, yet the amount of abraded material is increased. wave are acquired with optical profilometry. In Figure 9 the "time evolution" by scratching in machine direction on the DR- 8 sample is visualized. The numbers correspond to those of Figure 6a and Figure 7. Already after scratching for $200 \mu \mathrm{m}$, material from the pile-up on the sides of the scratch is pulled forward. As the scratch length increases, to $300 \mu \mathrm{m}$ and respectively to $400 \mu \mathrm{m}$, the fringes that indicate the material flow are originating from far behind the indenter tip. Upon further increasing the scratch length, the walls of the pile-up become increasingly steep. From frame number 6 onwards, the push-pad clearly becomes brittle and the scratch becomes narrower.

The discrepancy between HDPE and iPP is understood by combining the tensile response of the oriented tapes with the intrinsic material response, i.e. the true
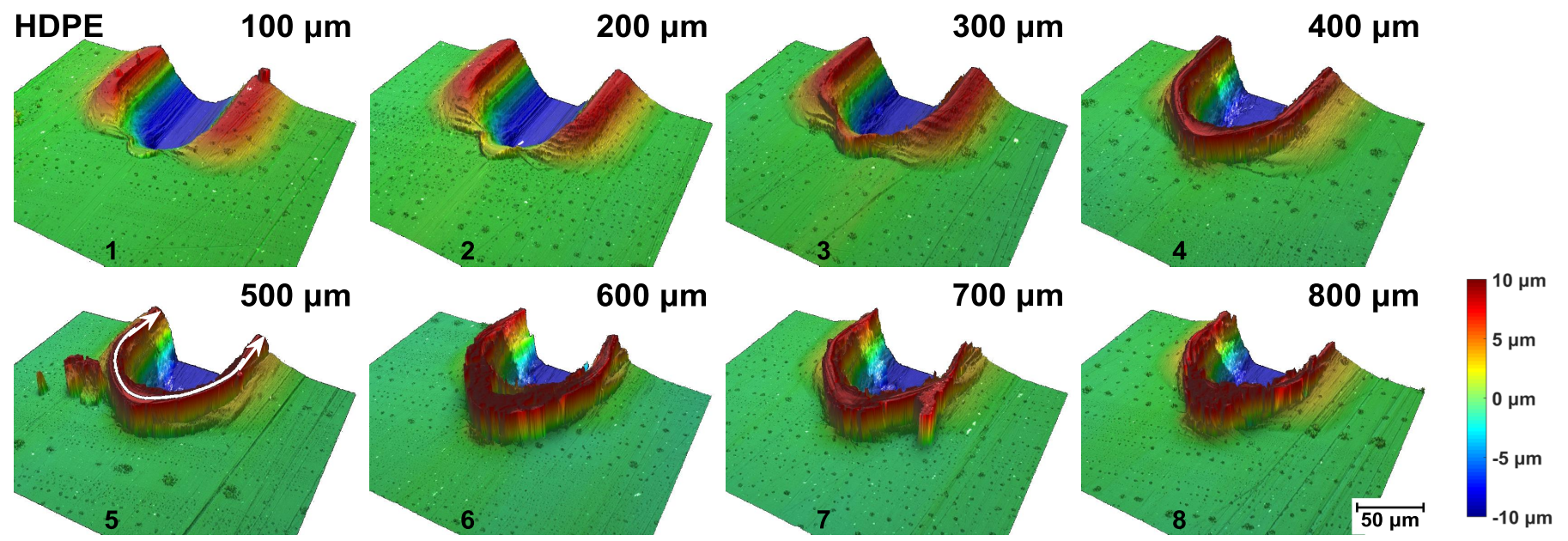

Figure 9: Residual bow wave after scratching oriented HDPE in machine direction. Numbers correspond to those in Figure 6a and Figure 7 Up to a scratch length of $400 \mu \mathrm{m}$ a bow wave builds-up and stabilizes. Upon further deformation, local brittle failure is observed in the bow wave, which eventually leads to local failure. The "strap" formed by large tensile stresses is indicated by the while arrow in the fifth frame. 

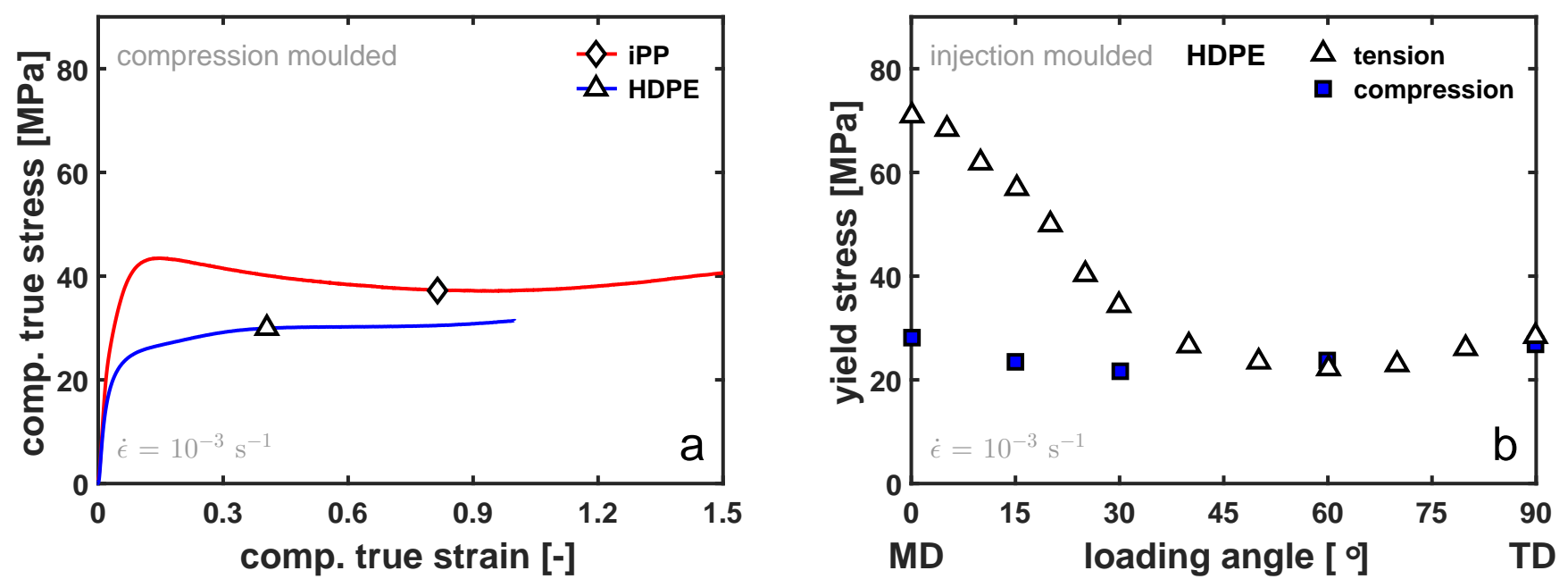

Figure 10: a) True stress-strain response of compression moulded, isotropic iPP (data adopted from Caelers et al. 37]) and HDPE (data adopted from Kanters et al. [36]). After yielding iPP displays a decrease in true stress (strain softening) and upon further deformation the true stress increases again (strain hardening). HDPE on the other hand, immediately hardens. b) Yield stress of anisotropic HDPE samples produced by injection moulding (data adopted from Senden et al. [38]). While the tensile stress is largely direction dependent, the compressive maximum stress is hardly affected by orientation.

stress-strain relation measured in uniaxial compression tests. As was already discussed before, the increase in maximum ${ }_{405}$ tensile stress by pre-stretching is more pronounced in iPP than in HDPE (Figure 2). Therefore the increase in maxinum stress compensates for the decrease in strain-at-break in the case of iPP, while in HDPE the decrease in strainat-break is hardly compensated. Another important differ-410 ence between the two materials is the intrinsic post-yield behaviour. Typical true stress-strain relations measured at 380 a strain-rate of $\dot{\epsilon}=10^{-3} \mathrm{~s}^{-1}$ are depicted in Figure 10a. After yielding, iPP shows a decrease in true stress, known as strain softening. This decrease in stress allows for strain ${ }_{415}$ localization, however the ductility of isotropic iPP is preserved by the subsequent increase in true stress, known as strain hardening. Isotropic HDPE on the other hand, exhibits after yield solely strain hardening. The ever increasing stress in this case limits the maximum strain. Besides 420 the difference between the two materials, a comprehensive understanding of the effect of orientation on the tensile and compressive response is key. The effect of load angle on the tensile yield stress is already extensively discussed. Figure 10b, adopted from Senden et al. [38, compares for ${ }_{425}$ an injection moulded HDPE sample the tensile and compressive yield stress. As may be trivial, the alignment of the crystalline network with respect to the test direction does not influence the compressive load bearing capacity significantly.

Recalling the complex stress field around an indenter tip, it is now possible to relate the deformation kinetics to ${ }^{430}$ the observed deformation and failure modes observed in scratching HDPE and comment on the discrepancies with iPP. At the moment of initial indentation, before the onset of sliding, a compressive force pushes material sideways.
Due to the highly anisotropic microstructure, a pile-up is formed in the direction parallel to the pre-tensioned network. At the onset of sliding, a small bow wave develops, equivalent to the case of iPP. The ability of iPP to localize stresses, makes the transverse direction always the direction of lowest resistance. Therefore the indenter tip is ever able to dispose material at the sides of the scratch, keeping the bow wave in front low and stable. The immediate strain hardening in HDPE makes the transverse direction not essentially the direction of minimal resistance. As a result the bow wave is able to keep growing upon sliding, and material from the pile-up on the sides is pulled forward, creating a "strap" around the indenter tip, see the fifth frame of Figure 9. Continuation of sliding leads to an increasing tension in this strap, lifting the tip while increasing the frictional resistance. Eventually, when the tensile stress in the bow wave exceeds its limit, the strap breaks (Figure 8), cleaving the bow wave, with brittle machining as a result. Thereafter, the tip slips over the remains of the bow wave, and the whole process repeats itself.

The combination of a lacking steady-state in the penetration depth, an increase in friction force because of a rapidly hardening bow wave and the occurrence of significant wear already after a single scratch, implies that orientation of HDPE reduces the scratch resistance in machine direction significantly.

\section{Conclusions}

The scratch response of isotropic and oriented high-density polyethylene (HDPE) is quantitatively assessed. With increasing applied load, the surface penetration and lateral force are increased. Due to the material's lower yield stress 
${ }_{435}$ as compared to isotactic polypropylene (iPP), the pene-495 tration depth in HDPE is higher. The frictional resistance however, is lower for HDPE as for iPP because HDPE displays pronounced strain hardening. As a result thereof, local stresses are better distributed and cracking, which500 leads to wear, is delayed.

In oriented HDPE the scratch resistance is improved in transverse direction as compared to isotropic material; increasing the lateral stiffness decreases the penetration505 depth and therewith the frictional force. In machine direction however, the scratch resistance is drastically decreased; because of extensive strain hardening, large tensile stresses are induced in the bow wave in front of the ${ }^{510}$ indenter tip. In the area where this tensile stress exceeds its limit, local fracture leads to a non-constant surface penetration and abrasive wear. With increasing prestretch, the strain-at-break under tensile loading is de-515 creased, while the maximum tensile stress is hardly increased, hence the wear rate increases with increasing amount of orientation, completely opposite to previous observations in oriented iPP systems. Counterintuitively, highly ${ }^{520}$ oriented samples display a remarkable elastic recovery after sliding in transverse direction. Hence, in applications with a preferred sliding direction, the orientation of HDPE crystals should be placed perpendicular to this sliding di-525 rection, in order to prevent damage of the contact layer.

\section{Acknowledgements}

The authors wish to thank Royal DSM N.V. for their valu- ${ }^{530}$ able assistance in sample orientation.

\section{References}

[1] J. Fu, B. W. Ghali, A. J. Lozynsky, E. Oral, O. K. Muratoglu, Wear resistant UHMWPE with high toughness by high temperature melting and subsequent radiation cross-linking, Poly-540 mer 52 (4) (2011) 1155-1162. doi:10.1016/j.polymer.2011. 01.017

[2] O. K. Muratoglu, C. R. Bragdon, D. O. O'Connor, M. Jasty, W. H. Harris, G. Rizwan, F. McGarry, Unified wear model for highly crosslinked ultra-high molecular weight polyethylenes545

475 (UHMWPE), Biomaterials 20 (16) (1999) 1463-1470. doi: 10.1016/S0142-9612(99) 00039-3

[3] A. A. Edidin, L. Pruitt, C. W. Jewett, D. J. Crane, D. Roberts, S. M. Kurtz, Plasticity-induced damage layer is a precursor to wear in radiation- cross-linked UHMWPE acetabular compo-550 nents for total hip replacement, Journal of Arthroplasty 14 (5) (1999) 616-627. doi:10.1016/S0883-5403(99) 90086-4

[4] S. A. Atwood, D. W. van Citters, E. W. Patten, J. Furmanski, M. D. Ries, L. A. Pruitt, Tradeoffs amongst fatigue, wear, and oxidation resistance of cross-linked ultra-high molecular weight555 polyethylene, Journal of the Mechanical Behavior of Biomedical Materials 4 (7) (2011) 1033-1045. doi:10.1016/j.jmbbm. 2011. 03.012

[5] E. Oral, K. K. Wannomae, N. Hawkins, W. H. Harris, O. K. Muratoglu, $\alpha$-Tocopherol-doped irradiated UHMWPE for high560 fatigue resistance and low wear, Biomaterials 25 (24) (2004) 5515-5522. doi:10.1016/j.biomaterials.2003.12.048

[6] F. Renò, M. Cannas, UHMWPE and vitamin E bioactivity: An emerging perspective, Biomaterials 27 (16) (2006) 3039-3043. doi:10.1016/j.biomaterials.2006.01.016
[7] B. J. Briscoe, P. D. Evans, S. K. Biswas, S. K. Sinha, The hardnesses of poly(methylmethacrylate), Tribology International 29 (2) (1996) 93-104. doi:10.1016/0301-679X(95) 00045-6.

[8] B. J. Briscoe, E. Pelillo, S. K. Sinha, Scratch hardness and deformation maps for polycarbonate and polyethylene, Polymer Engineering and Science 36 (24) (1996) 2996-3005. doi:Doi10. 1002/Pen.10702

[9] B. J. Briscoe, S. K. Sinha, Wear of polymers, Proceedings of the Institution of Mechanical Engineers, Part J: Journal of Engineering Tribology 216 (6) (2002) 401-413. doi:10.1243/ 135065002762355325

[10] W. Brostow, H. E. Hagg Lobland, M. Narkis, Sliding wear, viscoelasticity, and brittleness of polymers, Journal of Materials Research 21 (9) (2006) 2422-2428. doi:10.1557/jmr.2006. 0300

[11] B. J. Briscoe, Isolated contact stress deformations of polymers: The basis for interpreting polymer tribology, Tribology International 31 (1-3) (1998) 121-126. doi:10.1016/S0301-679X(98) 00014-0.

[12] B. J. Briscoe, S. K. Sinha, Scratch Resistance and Localised Damage Characteristics of Polymer Surfaces - A Review, Materwis Werkstofftech 34 (10-11) (2003) 989-1002. doi:10.1002/ mawe.200300687

[13] Y. J. Mergler, R. J. van Kampen, W. J. Nauta, R. P. Schaake, B. Raas, J. G. van Griensven, C. J. Meesters, Influence of yield strength and toughness on friction and wear of polycarbonate, Wear 258 (5-6) (2005) 915-923. doi:10.1016/j. wear.2004.09. 046

[14] W. Brostow, W. Chonkaew, R. Mirshams, A. Srivastava, Characterization of grooves in scratch resistance testing, in: Polymer Engineering and Science, Vol. 48, 2008, pp. 2060-2065. doi:10.1002/pen.21085

[15] J. H. Lee, G. H. Xu, H. Liang, Experimental and numerical analysis of friction and wear behavior of polycarbonate, Wear 251 (PART 2) (2001) 1541-1556. doi:Doi:10.1016/ s0043-1648(01) 00788-8

[16] J. L. Bucaille, C. Gauthier, E. Felder, R. Schirrer, The influence of strain hardening of polymers on the piling-up phenomenon in scratch tests: Experiments and numerical modelling, Wear 260 (7-8) (2006) 803-814. doi:10.1016/j.wear.2005.04.007.

[17] H. Jiang, G. T. Lim, J. N. Reddy, J. D. Whitcomb, H. J. Sue, Finite element method parametric study on scratch behavior of polymers, Journal of Polymer Science, Part B: Polymer Physics 45 (12) (2007) 1435-1447. arXiv:0406218, doi:10.1002/polb. 21169

[18] N. Aleksy, G. Kermouche, A. Vautrin, J. M. Bergheau, Numerical study of scratch velocity effect on recovery of viscoelasticviscoplastic solids, International Journal of Mechanical Sciences 52 (3) (2010) 455-463. doi:10.1016/j.ijmecsci.2009.11.006.

[19] H. Pelletier, C. Gauthier, R. Schirrer, Influence of the friction coefficient on the contact geometry during scratch onto amorphous polymers, Wear 268 (9-10) (2010) 1157-1169. doi: $10.1016 / j$.wear.2010.01.003

[20] Z. Wang, P. Gu, H. Zhang, Z. Zhang, X. Wu, Finite element modeling of the indentation and scratch response of epoxy/silica nanocomposites, Mechanics of Advanced Materials and Structures 21 (10) (2014) 802-809. doi:10.1080/15376494.2012. 707752

[21] M. M. Hossain, R. Minkwitz, P. Charoensirisomboon, H. J. Sue, Quantitative modeling of scratch-induced deformation in amorphous polymers, Polymer (United Kingdom) 55 (23) (2014) 6152-6166. doi:10.1016/j.polymer.2014.09.045

[22] B. Feng, Z. Chen, Tribology behavior during indentation and scratch of thin films on substrates: Effects of plastic friction, AIP Advances 5 (5) (2015) 057152. doi:10.1063/1.4921836

[23] L. C. A. van Breemen, L. E. Govaert, H. E. H. Meijer, Scratching polycarbonate: A quantitative model, Wear 274-275 (2012) 238-247. doi:10.1016/j.wear.2011.09.002

[24] S. Krop, H. E. H. Meijer, L. C. A. van Breemen, Finite element modeling and experimental validation of single-asperity sliding friction of diamond against reinforced and non-filled poly- 

2016.03 .014

[25] S. F. S. P. Looijmans, P. D. Anderson, L. C. A. van Breemen, Contact mechanics of isotactic polypropylene: Effect of prestretch on the frictional response, Wear 398-399 (2018) 183-190. doi: $10.1016 / j$.wear.2017.12.002

[26] C. Gauthier, R. Schirrer, Time and temperature dependence of the scratch properties of poly(methylmethacrylate) surfaces,

575 Journal of Materials Science 35 (9) (2000) 2121-2130. doi: 10.1023/A: 1004798019914

[27] I. Demirci, C. Gauthier, R. Schirrer, Mechanical analysis of the damage of a thin polymeric coating during scratching: Role of the ratio of the coating thickness to the roughness of a scratching tip, Thin Solid Films 479 (1-2) (2005) 207-215. doi:10.1016/ $580 \quad$ j.tsf.2004.11.194

[28] T. A. Tervoort, R. J. M. Smit, W. A. M. Brekelmans, L. E. Govaert, A Constitutive Equation for the Elasto-Viscoplastic Deformation of Glassy Polymers, Mechanics Time-Dependent Materials 1 (3) (1997) 269-291. doi:10.1023/A:1009720708029

[29] E. T. J. Klompen, T. A. P. Engels, L. E. Govaert, H. E. H. Meijer, Modeling of the postyield response of glassy polymers: Influence of thermomechanical history, Macromolecules 38 (16) (2005) 6997-7008. doi:10.1021/ma050498v

[30] L. C. A. van Breemen, E. T. J. Klompen, L. E. Govaert, H. E. H. Meijer, Extending the EGP constitutive model for polymer glasses to multiple relaxation times, Journal of the Mechanics and Physics of Solids 59 (10) (2011) 2191-2207. doi:10.1016/j.jmps.2011.05.001

[31] D. J. A. Senden, S. Krop, J. A. W. van Dommelen, L. E. Govaert, Rate- and temperature-dependent strain hardening of polycarbonate, Journal of Polymer Science, Part B: Polymer Physics 50 (24) (2012) 1680-1693. doi:10.1002/polb.23165

[32] L. C. A. van Breemen, T. A. P. Engels, E. T. J. Klompen, D. J. A. Senden, L. E. Govaert, Rate- and temperaturedependent strain softening in solid polymers, Journal of Polymer Science, Part B: Polymer Physics 50 (24) (2012) 1757-1771. doi:10.1002/polb.23199

[33] J. W. Housmans, M. Gahleitner, G. W. M. Peters, H. E. H. Meijer, Structure-property relations in molded, nucleated isotactic polypropylene, Polymer 50 (10) (2009) 2304-2319. doi: $10.1016 / j$.polymer.2009.02.050

[34] M. van Drongelen, T. B. van Erp, G. W. M. Peters, Quantification of non -isothermal, multi-phase crystallization of isotactic polypropylene :The influence of cooling rate and pressure, Polymer 53 (21) (2012) 1-12. doi:10.1016/j.polymer.2012.08.003

[35] T. B. van Erp, C. T. Reynolds, T. Peijs, J. A. W. van Dommelen, L. E. Govaert, Prediction of yield and long-term failure of oriented polypropylene: Kinetics and anisotropy, Journal of Polymer Science, Part B: Polymer Physics 47 (20) (2009) 20262035. arXiv:0406218, doi:10.1002/polb.21801.

[36] M. J. W. Kanters, K. Remerie, L. E. Govaert, A New Protocol for Accelerated Screening of Long-Term Plasticity-Controlled Failure of Polyethylene Pipe Grades, Polymer Engineering and Science 56 (6) (2016) 676-688. doi:10.1002/pen.24294

620 [37] H. J. M. Caelers, E. Parodi, D. Cavallo, G. W. M. Peters, L. E. Govaert, Deformation and failure kinetics of iPP polymorphs, Journal of Polymer Science, Part B: Polymer Physics 55 (9) (2017) 729-747. doi:10.1002/polb. 24325

[38] D. J. A. Senden, G. W. M. Peters, L. E. Govaert, J. A. W. van Dommelen, Anisotropic yielding of injection molded polyethylene: Experiments and modeling, Polymer 54 (21) (2013) 58995908. doi:10.1016/j.polymer.2013.08.047 